\title{
The Integration of Process
} Safety into a Chemical Reaction Engineering Course: Kinetic Modeling of the T2 Incident

\author{
Ronald J. Willey, ${ }^{a}$ H. Scott Fogler ${ }^{b}$, and Michael B. Cutlip ${ }^{c}$ \\ ${ }^{a}$ Department of Chemical Engineering, Northeastern University, Boston, MA; r.willey@neu.edu (for correspondence) \\ bepartment of Chemical Engineering, University of Michigan, Ann Arbor, MI; sfogler@umich.edu \\ cDepartment of Chemical Engineering, University of Connecticut, Storrs, CT; michael.cutlip@uconn.edu
}

Published online 6 December 2010 in Wiley Online Library (wileyonlinelibrary.com). DOI 10.1002/prs.10431

The explosion and subsequent death of four people at the T2 Laboratories, chemical facility in Jacksonville, Florida, USA, in 2007 has resulted in the United States Chemical Safety Board finding that undergraduate chemical engineering students do not receive adequate knowledge in the hazards associated with chemical processing. This article summarizes the events that led up to the T2 tragedy. A reactor engineering analysis of the event is presented that can be used in a chemical reaction engineering classroom to demonstrate the hazards involved when dealing with exothermic reactions and methods to mitigate. (C) 2010 American Institute of Chemical Engineers Process Saf Prog 30: 39-44, 2011

Keywords: process safety education; runaway reactions; reactor explosions

\section{INTRODUCTION}

\section{Description of the Accident}

On December 19, 2007 at 1:33 PM, a tremendous explosion shocked the northern Jacksonville, Florida region. Tons of sodium, hydrogen, and organics exploded into surrounding environment via a reactor rupture and caught fire [1]. The explosion occurred at a chemical producer called T2 Laboratories. Four

This was provided to us anonymously by a reviewer of the first draft of this work.

(C) 2010 American Institute of Chemical Engineers people lost their life. Thirty-two people within the vicinity suffered injuries. The power of the shock wave was felt 15 miles away. A video about the event is available to the public via the CSB website [2]. Figure 1 shows the resultant plant damage a day after the event. The plant manufactured methylcyclopentadienyl manganese tricarbonyl, a gasoline antiknock additive, for a third party distributor. At the time, a 2,450 gallon batch reactor was producing the first intermediate, sodium methylcyclopentadiene and hydrogen (a by-product) from the reaction of metallic sodium with methylcyclopentadiene. Diethylene glycol dimethyl ether (diglyme) was used as a solvent. This was the 175th batch manufactured by the facility.

\section{The Major Deviation that Fateful Day}

The underlying direct cause of the accident was the loss of cooling water to a reactor processing an exothermic reaction. A jacketed reactor, with the ability to transfer heat generated by reaction, was used. Figure 2 shows a cross-section of the reactor. Water was added to a cooling jacket that surrounded the reactor. Vaporization of the water inside the jacket carried away the heat released by the main reaction. Around 1:23 PM, a reactor operator contacted the one of the plant owners (a chemical engineer) informing him that there was no cooling water flow to the reactor.

What was normally a multihour exothermic process done at $350^{\circ} \mathrm{F}\left(176.7^{\circ} \mathrm{C}\right)$ became a 10 -min exo- 


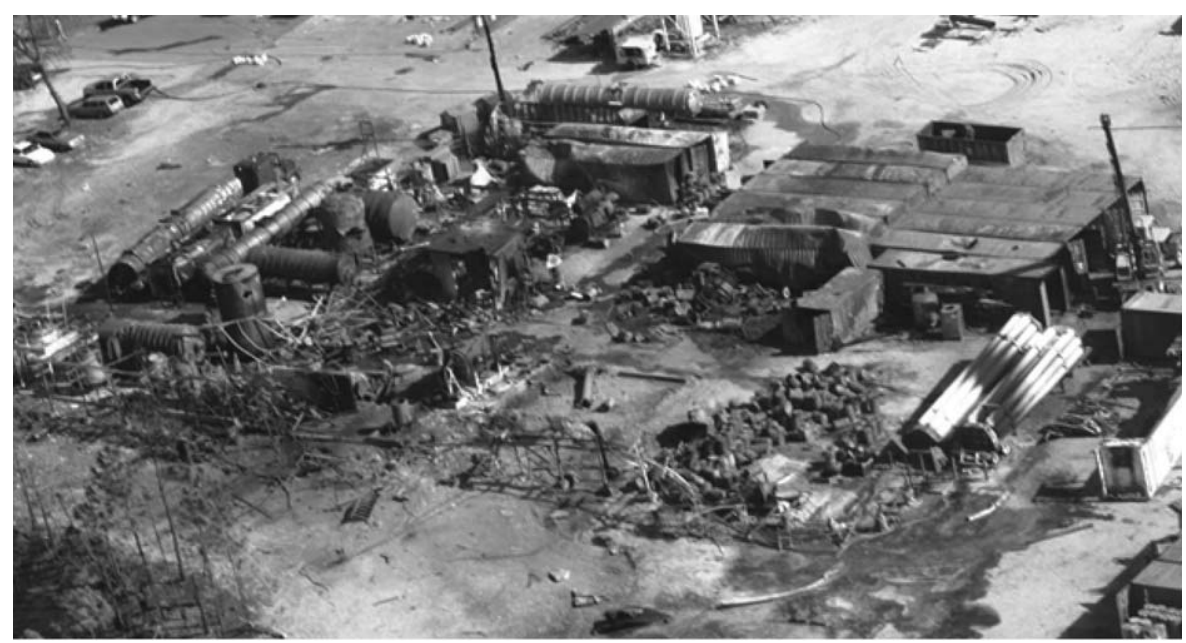

Figure 1. Overview of the accident scene shortly after the event. (CSB report, p. 3 Ref. 1).

thermic process. The reaction rate accelerated as described by the Arrhenius effect. More complicated, and unknown to the plant employees, was a critical temperature, $390^{\circ} \mathrm{F}\left(198.6^{\circ} \mathrm{C}\right)$, where a second, stronger, exothermic reaction kicked in, the decomposition reaction of diglyme either catalyzed or enhanced by the presence of sodium. This rapid decomposition led to the creation of gases and vapors at a very rapid rate. Quickly, the rate of gas generation exceeded the 4 "-diameter relief system's ability to relieve the reactor without further build up of pressure and eventual explosion. Within minutes of the recognition of the hazardous situation, the reactor exploded.

\section{CSB Major Recommendations Include Changes in Safety Education of Chemical Engineers}

A major finding from the CSB investigation was that fundamental faults lie within the educational preparations of chemical engineering students. The owners and engineers involved with T2 had little background in dealing with reactive chemicals tracing all the back to their chemical engineering undergraduate educational preparation. The CSB recommendations were [3]:

American Institute of Chemical Engineers

2008-03-I-FL-1: Work with the Accreditation Board for Engineering and Technology to add reactive hazard awareness to baccalaureate chemical engineering curricula requirements.

2008-03-I-FL-2: Inform all student members about the (AIChE) Process Safety Certificate Program and encourage program participation.

\section{Accreditation Board for Engineering and Technology}

2008-03-I-FL-3: Work with the American Institute of Chemical Engineers to add reactive hazard awareness to baccalaureate chemical engineering curricula requirements.

\section{Present Resources Available for Safety Education}

A major resource group for safety education sources is through the Center for Chemical Process Safety of the AIChE and its subcommittee called Safety and Chemical Engineering Education. This group of industrialists, academics, and government representatives has been offering materials for chemical engineering education for more than 20 years. Their website is http://www.sache.org. Publications describing the group's efforts are available in Refs. 4-11, and 12.

\section{Reactor Analysis/Modeling}

The analyses of exothermic reactions are not trivial. If heat transfer is involved, independent variables on conversion included all reactor starting concentrations, reactor temperature, coolant temperature, and time. All have nonlinear effects on conversion. For example, increasing temperature can accelerate a reaction rate when temperature control is lost. The heat released by the reaction is absorbed by the contents within the reactor. The contents heat up. The reaction goes faster. The contents heat up more. The reaction goes even faster. This response is commonly known as a runaway reaction. Under severe circumstances, reactor failure can occur due to high pressure as a result of gaseous product generation and the presence of high temperatures. Each species within the reactor volume has a differential equation based on the mass (mole) balance. The energy balance around the reactor creates another differential equation. When the vapor phase is included, at least one more differential equation evolves. Finally, there is the challenge of determining properties, especially when the mixture is nonideal. Sophisticated programs are available that can combine properties prediction and exothermic reaction analysis together such as SuperChems by IoMosaic [13]. An example of the use of SuperChems in the modeling 


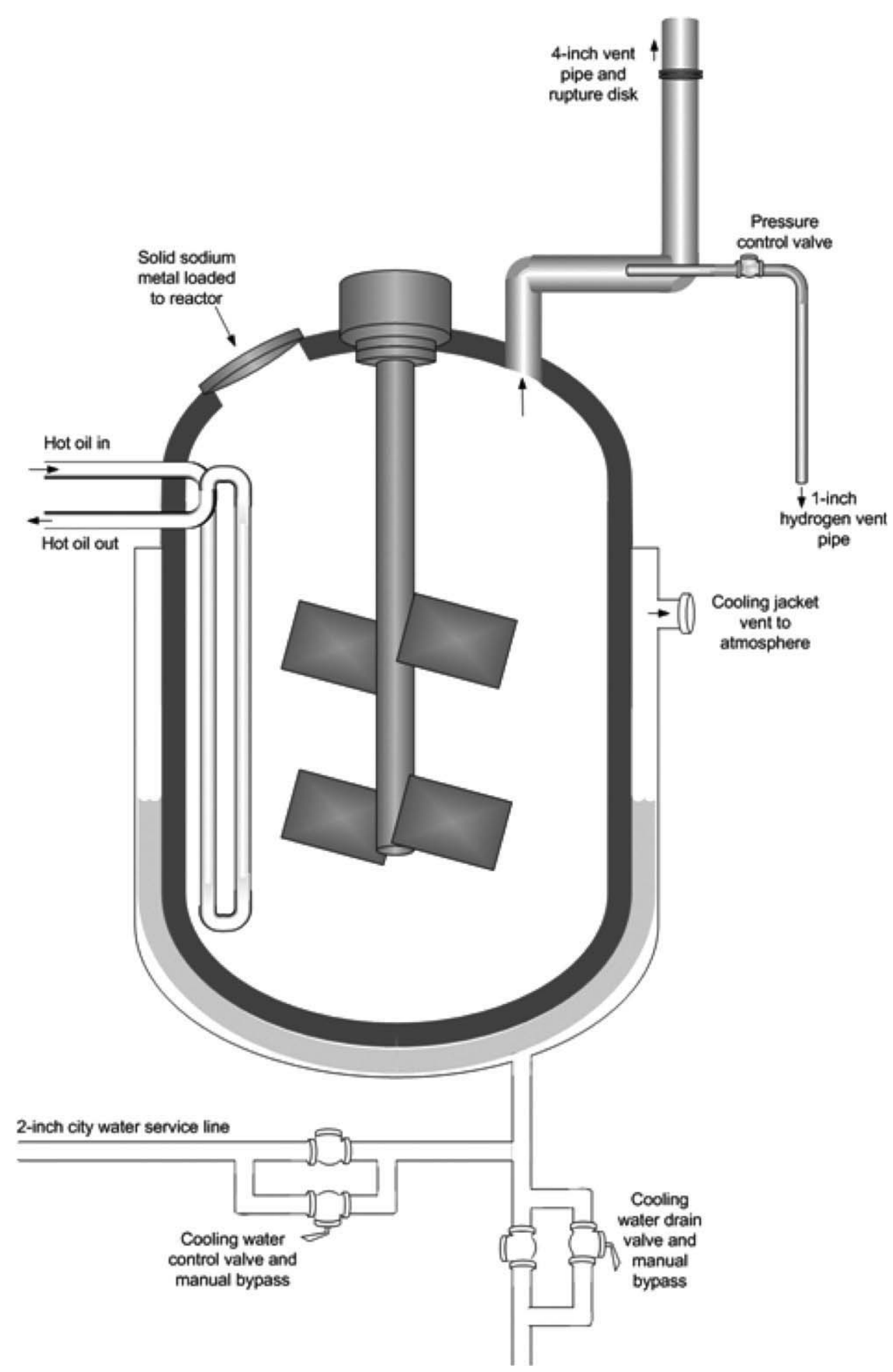

Figure 2. Cross sectional view of the reactor. Note that the jacketed cooling zone (light grey) which used evaporation of water to remove the heat generated by the reaction. (CSB report, p. 20, Ref. 1).

of a complex exothermic reaction is presented in a paper by Willey et al. [14]. However, this program is not easily accessible to chemical engineering students and requires substantial instruction to understand. In this work, we explore an intermediate approach that offers students more accessible tools.

\section{METHODS}

\section{Reaction Stoichoimetry Selected}

The CSB report offers details of the chemistry about the reactions used at T2 in the report's Appendix A [1]. The exothermic reaction occurring at the time of the accident was related to the first step: the 
Table 1. Batch reactor feed contents taken for the "normal" reactor run (VSP2 Run 6 CSB report) [1].

\begin{tabular}{|c|c|c|c|c|}
\hline Chemical & $\begin{array}{l}\text { VSP2 Run } \\
\text { (grams) }\end{array}$ & Weight \% & $\begin{array}{c}\text { Mass used } \\
\text { for simulation } \\
\text { discussed below } \\
(\mathrm{kg})\end{array}$ & $\begin{array}{l}\text { Concentration } \\
\text { used for simulation } \\
\left(\mathrm{mol} / \mathrm{dm}^{3}\right)\end{array}$ \\
\hline Sodium & 5.147 & 10.59 & 593 & 4.3 \\
\hline MCDP dimer & 21.164 & 43.55 & 2,452 & 2.55 \\
\hline Diglyme & 20.690 & 42.58 & 2,415 & 3 \\
\hline Mineral oil & 1.591 & 3.28 & 185 & 0.088 \\
\hline
\end{tabular}

combination of sodium and methylcyclopentadiene to sodium methylcyclopentadiene and a 0.5 mole of hydrogen. Further, the report noted that a second, previous unknown, exothermic reaction followed the decomposition of the solvent, diglyme, in the presence of sodium. Decompositions are very complicated. They do not go completely to the lowest energy products such as water or carbon dioxide. Often, a complex residue is left behind composed of carbon and hydrogen, and is essentially, best referred to as tar. The CSB report did not present the detailed chemical analysis of the products produced when diglyme decomposes, however, diglyme contains 3 atoms of oxygen, 6 atoms of carbon, and 14 atoms of hydrogen. We used this to imagine that when the diglyme decomposed, three moles of permanent gas (either $\mathrm{CO}$ or $\mathrm{H}_{2}$ ) formed. It is this formation of a permanent gas, into confined space along with the increasing vapor pressure due to higher temperatures that created the rapid rise in pressure, and subsequent vessel failure.

The CSB report provided figures of reaction calorimetry studies completed for pure diglyme in the presence of sodium, and for a reactant mixture representative of normal operation. A VSP2 calorimeter was used in which background can be read in a PSP article by Theis et al. [15]. The VSP2 results demonstrated conclusively that the diglyme in the presence of sodium rapidly decomposes when the temperature exceeded $390^{\circ} \mathrm{F}$. The pressure and temperature rise during this exothermic reaction at it peak conditions was about 32,000 psig per minute and $2,340^{\circ} \mathrm{F}$ per minute, respectively [1]. We modeled the second reaction as a first-order decomposition with an activation energy of $80 \mathrm{~kJ} \mathrm{~mol}^{-1}$. Essentially, the first trace of exothermic activity is shown around $358^{\circ} \mathrm{F}$ and the start of the runaway is noted at $390^{\circ} \mathrm{F}$. For the reaction of sodium with methylcyclopentadiene, we estimated an activation energy of $40 \mathrm{~kJ} \mathrm{~mol}^{-1}$, again using VSP2 data for guidance.

Several other parameters had to be estimated to reach a working model for the two reactions involved. These were the composition loaded into the reactor (we used the same mass fractions as given in Table 1). For the amount loaded into the reactor, we selected a level of two-thirds full based on the video presented by the CSB on the accident that shows this level in the reactor [2]. This equates to $6,000 \mathrm{dm}^{3}$ (or liters) of liquid and $3,000 \mathrm{dm}^{3}$ of "head space" or gas space within the reactor. The heat of reactions were initially estimated via Aspen simulation software [16], and later slightly adjusted to match the temperature rise shown in the CSB report [1]. These values were $-45 \mathrm{~kJ}$ per mol of sodium reacted to products and $-390 \mathrm{~kJ}$ per mol of diglyme decomposed, respectively. We also needed heat capacity of the liquid reaction mixture plus the reactor shell that was estimated to be a sum of $16 \mathrm{MJ} \mathrm{K}^{-1}$ for the entire mass of the reactor mixture and reactor mass $\left(\Sigma m_{i} c_{\mathrm{pi}}\right.$ of liquid contents and reactor material). As we worked on the model, we included an energy term for the vaporization of diglyme. Vaporization tempers the heating effect within the reactor because a portion of the heat released by reaction is used to vaporize the solvents within the reaction. For example, if the reactor's rupture disk had open at 75 psig, then the rapid vaporization of the reactor contents would have cooled the reactor and prevented the reactor contents from moving into the critical region where diglyme decomposition accelerates.

\section{Reaction Model Development}

Kinetic Models Used

Reaction 1 (normal process reaction).

$\mathrm{C}_{6} \mathrm{H}_{8}+\mathrm{Na} \rightarrow\left[\mathrm{C}_{6} \mathrm{H}_{7}^{-} \cdots \mathrm{Na}^{+}\right]+0.5 \mathrm{H}_{2}+$ heat

Kinetic rate model used: $-r_{\mathrm{C}_{6} \mathrm{H}_{8}}=k_{1}\left[\mathrm{C}_{\mathrm{Na}}\right]\left[\mathrm{C}_{6} \mathrm{H}_{8}\right]$, mols $\mathrm{dm}^{-3} \min ^{-1}$. With $k_{1}=k_{1 \mathrm{~A}} \exp \left(-E_{1} / R T\right), \mathrm{dm}^{3}$ $\mathrm{mol}^{-1} \min ^{-1}$

$k_{1 \mathrm{~A}}=400 \mathrm{dm}^{3} \mathrm{~mol}^{-1} \mathrm{~min}^{-1}$ and $E_{1}=40,000 \mathrm{~J}$ $\mathrm{mol}^{-1} \mathrm{~K}^{-1}$

\section{Reaction 2 (diglyme decomposition reaction).}

$\mathrm{C}_{6} \mathrm{H}_{14} \mathrm{O}_{3} \rightarrow 3$ moles of gas + a liquid or solid residual + heat

Kinetic rate model used $-r_{\mathrm{C}_{6} \mathrm{H}_{14} \mathrm{O}_{3}}=k_{2}\left[\mathrm{C}_{6} \mathrm{H}_{14} \mathrm{O}_{3}\right]$, mols $\mathrm{dm}^{-3} \mathrm{~min}^{-1}$. With $k_{2}=k_{2 \mathrm{~S}} \exp \left(-E_{2} / R T\right) \mathrm{min}^{-1}$ $k_{2 \mathrm{~S}}=1 \times 10^{6} \mathrm{~min}^{-1}$ and $E_{2}=80,000 \mathrm{~J} \mathrm{~mol}^{-1} \mathrm{~K}$

\section{Reactor Type}

The reactor type used was a batch reactor with the ability to bleed off pressure via a $1^{\prime \prime}$ line. Should the pressure exceed the rupture disk rating, the rupture disk would burst and vent the reactor. The venting 


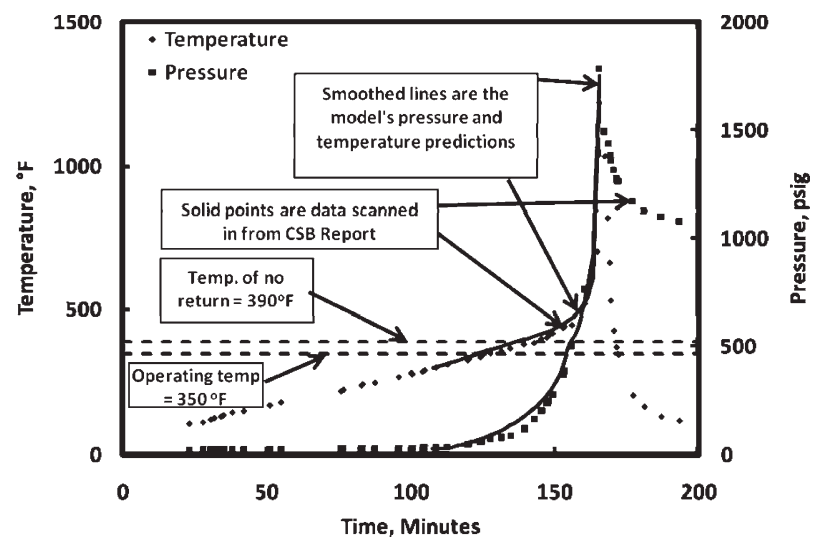

Figure 3. Matching of reaction model with VSP2 data offered for mixture as shown in the CSB T2 report, Figure 18.

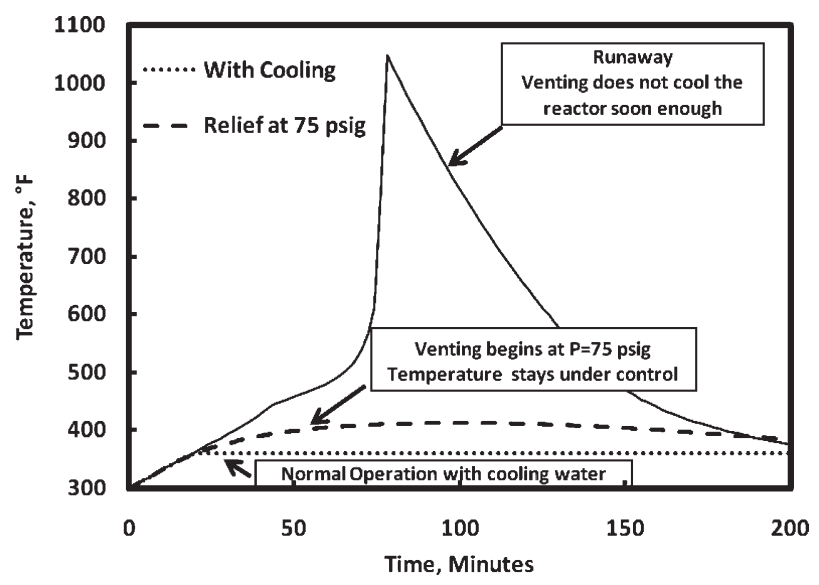

Figure 4. Temperature as a function of time for the three scenarios investigated in this work.

equation was only focused on the 4 " line. The venting was modeled proportional to the absolute pressure in the reactor assuming critical flow of vapor through line.

\section{Process Simulation by Polymath}

Polymath is a software program developed by $\mathrm{Mi}$ chael B. Cutlip et al. [17] for general use in chemical engineering and includes differential equations solving. It is geared to the chemical engineering student, and its programming is straightforward. Fogler integrates Polymath examples throughout his reaction chemical engineering textbook [18]. Many examples are presented to assist students and others in the use of this important mathematical tool. Educational and professional versions of Polymath are available at moderate prices [19]. Inexpensive site licenses of the educational student version are available via the CACHE web site [20].

\section{RESULTS}

The Polymath code used in the simulation is available from the authors. Verification of the model running adiabatically is compared against the CSB's

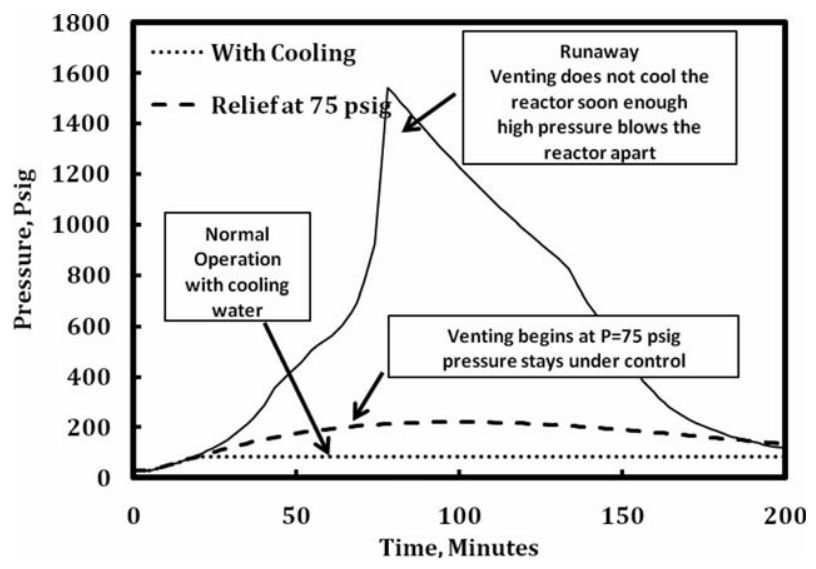

Figure 5. Pressure as a function of time for the three scenarios. Note the rapid pressure rise for the relief opening occurring at 400 psig.

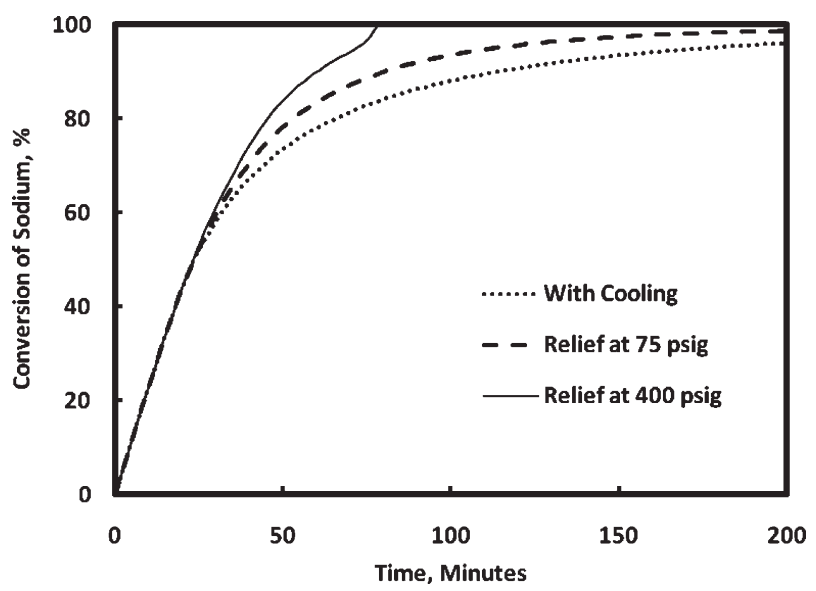

Figure 6. Conversion of sodium the limiting reactant within the reactor.

reported VSP2 data, which is shown in Figure 3. Three scenarios were then simulated: (1) normal operation, with a cooling water added to maintain the reactor temperature at $350^{\circ} \mathrm{F}$; (2) operation without cooling water (an adiabatic reactor) with a rupture disk opening set at 75 psig; and (3) an adiabatic reactor with a rupture disk opening set at 400 psig. Temperature and pressure profiles are shown in Figures 4 and 5 for the three scenarios. It is clear that the reactor never exceeds $390^{\circ} \mathrm{F}$ if cooling water is present. If the rupture disk opens at 75 psig, the reactor continues to heat and pressurize but at a slow rate, and eventually cooling occurs due to internal vaporization. On the other hand, venting the reactor at 400 psig leads to a runaway, as the reaction pressure generation rate far exceeds the cooling offered by the vaporization. The results happen very rapidly, within a few minutes once the temperature passes $500^{\circ} \mathrm{F}$. Figure 6 shows the conversion profiles of sodium, which represents the normal desired reaction for the three scenarios. Figure 7 shows the conversion of diglyme for the three scenarios. When run- 


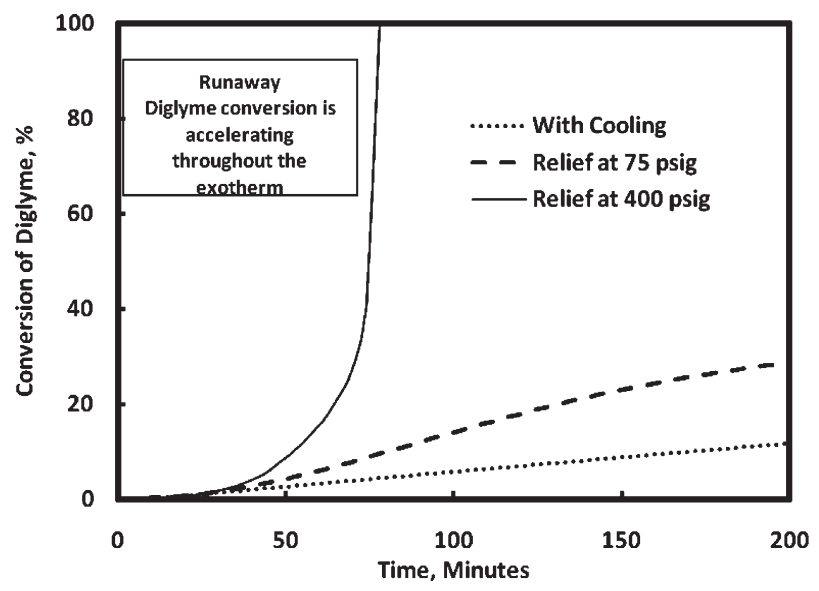

Figure 7. Conversion of diglyme for the three scenarios. Runaway occurs for rupture disk setting of 400 psi.

away occurs, it is the rapid conversion of diglyme that causes the explosion.

\section{DISCUSSION}

This case study is an excellent example of runaway batch reactions, and can be explained to the students of chemical engineering at several levels. At the undergraduate level, one can point out that every exothermic batch reaction deserves respect and understanding. That test mixtures should be run at the small scale in thermochemistry instruments such as Differential Scanning Calorimeter (DSC), Vent Sizing Package (VSP), and Accelerating Rate Calorimeter (ARC). That the test runs should include all reactants, solvents, and products to insure that the thermochemistry is understood at the microscale first. This point can be mentioned even in organic chemistry classes discussing exothermic organic reactions. At the next level, undergraduate reactor engineering, the hazards associated with scale up and processing reactions in batch reactors can be pointed out using this example. The CSB online video adds to the classroom presentation. At the graduate level, students can review the details of the model presented in this article, look at the assumptions, and improve on the predictability, in an effort to understand what details are needed to predict runaway reactions. For the practitioner, we offer techniques to simplify a complicated system, methods to estimate activation energy and system properties, plus the use of an easy to use differential equation solver that makes examining the system facile.

\section{LITERATURE CITED}

1. U.S. Chemical Safety and Hazard Investigation Board Investigation, Report No. 2008-3-I-FL September 2009, Available at: http://www.csb.gov/ investigations/detail.aspx SID $=8 \&$ Type $=2 \& p g=$ 1\&F_InvestigationId=8? Accessed on July 5, 2010.

2. CSB, Available at: http://www.csb.gov/video room/detail.aspx? VID $=32$. Accessed on July 5, 2010.

3. CSB, Available at: http://www.csb.gov/recom mendations/details.aspx?SID =8. Accessed on July 5, 2010.

4. D.C. Hendershot, A history of process safety and loss prevention in the American Institute of Chemical Engineers, PSP 28 (2009), 105-113.

5. D.A. Crowl, A century of process safety-And more, PSP 28 (2009), 103-104.

6. J.F. Louvar, Safety and chemical engineering education-History and results, PSP 28 (2009), 131-134.

7. D.C. Hendershot and W. Smades, Safety culture begins in the classroom, PSP 26 (2007), 83-84.

8. J.F. Louvar and D.C. Hendershot, Education materials for universities and industry, PSP 26 (2007), 85-89.

9. J.F. Louvar and F.O. Kubias, Safety and chemical engineering education, PSP 13 (1994), 72-74.

10. L. Osborn, Process safety in education, PSP 18 (1999), W5-W6.

11. R.J. Willey, SACHE case histories and training modules, PSP 18 (1999), 195-200.

12. F.O. Kubias and J.F. Louvar, Upgrading education and safety performance: SACHE at 17, PSP 21 (2002), D2-D4.

13. IoMosaic, Available at: http://www.ioiq.com/ superchems/overview.aspx. Accessed on July 10, 2010.

14. R.J. Willey, F. Rodrigues, S. Chippett, G. Melhem, and S.K. Singh, Thermo-kinetic analysis of reactions involved in the manufacture of o-nitroaniline, PSP 20 (2001), 123-129.

15. A.E. Theis, J.P. Burelback, and C.F. Askonas, Safety scale-up processes and accommodate recipe changes, PSP 28 (2009), 135-140.

16. Aspen Technology Inc. Available at: http://www. aspentech.com/. Accessed on July 10, 2010.

17. M. Shacham, Michael B. Cutlip, and M. Elly, Polymath Numerical Computation Package, 2010.

18. H.S. Fogler, Elements of Chemical Reaction Engineering, 4th Edition, Upper Saddle River, NJ: Prentice Hall Inc., 1999.

19. http://www.polymath-software.com/order/in dex.htm. Accessed on July 8, 2010.

20. http://www.che.utexas.edu/cache/polymath. html. Accessed on July 8, 2010. 